\title{
Converging Media and Modes: Digital Textuality and the Dissolution of Media Borders in Steven Hall's The Raw Shark Texts
}

\author{
Lai-Tze Fan
}

This paper discusses recent transformations of literature relative to the influence of digital media on culture and communication. Digital media and communication methods, I argue, encourage us to think of textuality in ways that converge media, treating them as dynamic, cross-referential, and interactive. I seek to examine the emergence of a digital textuality and to trace its impact on literary texts in three interrelated areas: first, new comprehensions of 'reading' and 'the text;' second, shifts to our conceptions of 'the literary' in the face of digital poetics and aesthetics; and third, ensuing tensions between posthuman and human agency concerning language, communication, and storytelling.

As a case study, this paper analyzes Steven Hall's The Raw Shark Texts (2007) for its formal experimentation and its mediations of medium, mode, and language. I examine how this text utilizes multimodality as a narrational device in order to imitate and explore the presence and implications of digital textuality. Insofar as this novel uses multimodality to mediate digital media, it demonstrates the literary value of converging media and modes of communication and also speaks to ensuing changes to how we define the literary and the future of literature in a digital age.

First of all, what is convergence? Henry Jenkins examines convergence with regard to the frameworks of media, economy, and the consumer audience, considering various treatments of converging information and content $(2008,17,18)$. 
This paper homes in on the convergence of media and their unique modes of meaning-making, arguing that this convergence establishes new understandings of textuality. Convergence is linked to the computer by Peter Lunenfeld who argues that it offers "the universal solvent into which all difference of media dissolves into a pulsing stream of bits and bytes [...] [The computer] combines the creation, distribution, and spectatorial functions of a vast variety of other media within one box" (2001, 7-8). For example, a text in which media and modes converge could take the form of a webpage on which one may read words while also listening to audio material, watching videos, and viewing pictures.

The examination of media convergence in terms of digital media and specifically the computer finds an antecedent in multimodal studies. Emerging from the field of social semiotics, multimodal studies examine how several modes of meaning-making in a text (such as sight and sound) can create a unique reading experience. Gunther Kress defines a mode as a "socially shaped and culturally given semiotic resource for making meaning" and he discusses the ways in which different modes have different potentials for meaning-making $(2010,79)$. The 'stuff' of sound can give way to such modes as music, film soundtracks, speech, and so forth; modes are therefore methods of communication that appeal to senses, to affect, and also to culturally specific needs $(79,80)$. A deaf community, for instance, requires a mode of sign language in order to communicate, and this form of cultural specificity is the reason Kress states that modal change tracks social change (82). By tracing the presence and usage of modes, we may also trace the current development and cultural impact of communication technologies and tools.

A society in which digital media are a dominant communication technology will exercise digital communication methods until it is accustomed to these methods and will then rely upon them. Finally, digitally friendly modes will become necessary in this society. It is therefore no coincidence that multimodal research has been taken up by studies of new media. In the case of a culture in which digital media are dominant communication tools, what may be deemed normal in communication practices is the use of multiple modes in the process of meaningmaking and the interrelations among different media as a new way of reading. Since the early 2000s, multimodal studies have been anchored towards the study of digital media as well, as scholars have identified that digital media easily enable multimodality (Jewitt and Kress 2003; Unsworth and Clérigh 2009). Current studies have argued that unimodal text-only documents increasingly wane because media have evolved with enhanced capabilities to hold and display texts in various modes, including graphics, pictures, layout techniques, and so forth (Goodman qtd. in Lim, Nekmat, and Nahar 2011, 169). Simply put, digital media do multimodality better and have caused information and thought to undergo conceptual changes in a digital environment. This is what Kress calls a representation revolution $(2003,116)$. 
Literary and cultural studies scholar Alan Liu has identified changes to representation in practice, linking them to the creation of a connective logic that is "expressed geopolitically as globalism, technologically as networking, and artistically as intertextuality, appropriation, sampling, and so on" (2004, 2; emphasis in the original). While I am wary of loaded terms such as 'revolution' to describe technology and its impact on society and culture, Liu's observations do suggest that a connective system has emerged with new information and aesthetic practices. Alternative methods of how to read and of where to locate information and the reader begin to dissolve the idea of static media borders altogether. Although media forms and formats are often understood to be autonomous, digital media encourage their convergence, initiating shifts to notions of 'the text' proper. New conceptions of 'text' and 'textuality' are confirmed by rapidly emerging scholarship on media convergence in various terms, including media adaptation, intermediality, multimodality, transmediality, and multimediality (Herman 2004; Cranny-Francis 2005; Nørgaard 2009; Grishakova 2010; Gibbons 2010; 2012).

In the consideration of the implications of digital textuality for literature, a critical and cultural examination should not only analyze literary texts that participate in the convergence of media and modes but should also align media convergence with larger shifts to communication as brought on by digital media. To better understand convergence culture as it plays out in literature, it is necessary to discuss the communication methods of digital media and new media.

To date, there is no more informed typology of new media language and logic than Lev Manovich's The Language of New Media (2001). For the purpose of discussing Manovich's text, I will echo his use of the term 'new media' to describe new information and communication technologies that are informed by the computer; however, this paper privileges the term 'digital media' in order to identify the computer form by name. Scholars of media archaeology such as Lisa Gitelman (2008) have shown that emerging media are always already perceived as 'new.' By cautioning against claims of revolution, the lens of media archaeology encourages researchers to contextualize emerging media and their communication practices regarding their histories and sociocultural and political environments (Chun 2006; Nerone 2006).

Manovich illustrates that new media have their own logic and language of form, production, and meaning-making. He defines his use of the term 'language' as an umbrella term for new media conventions to organize data and to structure the user's experience, and he notes that history has been composed of "a succession of distinct and equally expressive languages, each with its own aesthetic variables, and each closing off some of the possibilities of its predecessor" (Manovich 2001, 7, 8). Manovich describes several principles of computer-based media that are especially pertinent for analyzing practices of media convergence and for describing what is unique about digital media language and communication. The principle of numerical representation explains that new media are composed of digital code and that each new media object is made up of discrete units of data 
that are then organized into groups, wherein they have different functions (27-29). The principle of modularity builds on this logic: each unit is stored separately and has independent functions (30). The principle of automation describes the automatic execution of programming commands for media creation, manipulation, and access (32). In high-level automation, the computer can generate data and media through algorithms (32). The principle of variability holds that the semiotic placement of discrete data units into groups, and of the groups into sections, creates a branched structure in new media (38). This network structure is the reason that new media are often interactive, as a user must navigate through a selection of branches in order to operate the new media object (38). These principles have led Manovich to argue for a cultural sensibility in the information age that he calls the "computerization of culture" (9). Through this change, existing formal systems are redefined and new cultural forms begin to emerge (9). The final principle of transcoding describes how such changes begin, as the materiality of the computer affects its aesthetic and cultural possibilities $(46,47)$.

By fostering an understanding of information and information processing in these terms, new possibilities for aesthetics and composition surface, giving way to the textual elements of multimodality and multilinearity. A digital textuality is established, allowing us to think of reading as interactive and multilinear (Lankshear and Knobel 2008), of the reader as user or worker (Liu 2004), the text as permeable (Landow 2006; Kirschenbaum 2008), and the author as diminished in cultural and textual significance (Aufderheide 2013). In effect, questions arise of how we may define 'literature' and 'the literary' relative to new forms of literature. Scholars of electronic literature, including Michel Chaouli (2005), Marjorie Perloff (2009), and Marie-Laure Ryan (2004; 2010), have sought to shape a poetics of digital media. In particular, Ryan (2002) attempts to reconcile narrative linearity and digital multilinearity by examining interactive narratives, and Adalaide Morris (2009) argues for the literary value of a digital poetics in its own right. Kenneth Goldsmith (2011) further reshapes conceptions of literature by arguing that digital media language has altered how we view the roles of the writer and reader (15) and that computer code possesses literary value (19).

Shadowing this discourse of digital textuality and poetics is the fear of the "destruction" of a print-based literature in the digital age (Liu 2004, 3). For example, Kathleen Fitzpatrick argues that the computer "diminishes" the print novel by encouraging us to think about textuality and literature in new ways $(2002,522)$. The re-evaluation of literary texts in these terms has sparked theories of a "postprint" era or culture (Robertson 2013). However, media and literary scholars alike have proposed the possibility of mediating digital textuality vis-à-vis changes to the status of print texts and the literary. For example, in "The Future of Literature: Print Novels and the Mark of the Digital" (2008), N. Katherine Hayles argues that contemporary print literature reveals its being influenced by digital language and textuality by reacting and responding to these (162). She asserts that print literature acknowledges digital textuality through two complementary strategies: first, the 
imitation of digital textuality in rhetoric and style, and second, the emphasis of traditional literary devices (162). Liu foregrounds a "peculiarly edgy blend of aesthetics and critique" $(2004,8)$ as a critical strategy that can subvert the destruction of the literary; this strategy is described as a "future literary" (8).

Liu's and Hayles's works show that altered notions of the text call for studies of the consequences of digital materiality and reception for literary texts. This paper responds by proposing that contemporary print literature may adapt to the threat of literary destruction and a speculated post-print era. I propose that this self-reflexive literature may perform this adaptation by appropriating digital aesthetics and formal features, while also exposing and challenging the digitally informed communication practices and paradigms from which they are wrought.

To provide an example, I will analyze The Raw Shark Texts. Following up on Hayles, I will argue that this print novel engages in media convergence by simulating the aesthetics and formal features of digital media and modes. At the same time, it emphasizes traditional literary devices found in print narratives. By experimenting in this way, The Raw Shark Texts mediates tensions between digital and print media systems and navigates interrelations between various communication media and modes, including ideas of 'language' itself. The novel provides a critical commentary on media convergence and adaptation as having sociocultural effects on language for the human and language for the posthuman.

An unease towards digital textuality may be identified in the larger body of this self-reflexive and adapting literature. Fitzpatrick describes this phenomenon as an "anxiety of obsolescence" (2002, 6), which she analyzes in literary content as a concern of the human writer over posthuman language and agency. Digital media, Manovich shows, function through their own language and may perform this language in an automated way. Many literary writers and scholars have been made anxious by digital automation in generating creative texts, as it can eliminate the human from the process of writing creative literature. In the frame of digital textuality, I am interested in the way in which the "anxiety of obsolescence" is expressed not only in literary content, but also in literary form. I argue that The Raw Shark Texts demonstrates Hayles's argument as the novel recognizes digital textuality and culture and responds in two ways: first, by replicating the formal features of digital textuality through multimodality, and second, by mediating the relationship between digital and print media systems in a critical examination of the repercussions of digital textuality, including the phenomenon of a posthuman language.

The Raw Shark Texts is the story of Eric Sanderson who wakes up in a house that he does not remember, without recollection of who he is or any of his past. He finds a letter explaining that his 'self' has been consumed by a Ludovician, a shark-like organism made out of pure thought, which lives in a conceptual space of information, much like cyberspace. The Ludovician and other conceptual fish are described as parasites that feed on humans for their varied human components, from behavioural features to entire lifetimes of memories. The letter is signed "the First Eric Sanderson" (Hall 2007, 11), making our protagonist the Second Eric 
Sanderson. While seeking answers about his former past, Eric 2 learns that his girlfriend Clio died in a scuba diving accident and that Eric 1 released the Ludovician in an attempt to preserve and essentially resurrect Clio in the shark's conceptual space. His plan backfired when the shark instead chose him as a target to hunt. As the Ludovician failed to consume Eric entirely, he was brought back to the material world as Eric 2.

The Raw Shark. Texts functions as much more than a word-based text. It includes mailed letters, codes to be deciphered with a QWERTY keyboard and Morse code, postcard photos, sections of textbooks, a visualization of an explosion, and pictures of organisms that are made out of letters, numbers, words, and computer code. Perhaps most interesting of all - and most divergent from the medial singularity that we may associate with the novel form - are the negative chapters, which author Steven Hall wrote to accompany each book chapter. These have been hidden online and in the material world as a paratextual scavenger hunt. To date, six chapters have been discovered, one of them taped under a park bench.

While traditional literary narratives unfold across time, The Raw Shark Texts calls attention to its materiality by allowing the narrative to transpire over the space of pages - a narratological experiment that exemplifies multimodality. The depictions of movement are generally prefaced by Eric 2's narration just moments before physical movement occurs. For example, when running away from the Ludovician's second attack, the sound and placement of his feet are represented across the printed page: "thud thud thud thud" (156). The sound of his footsteps, the word depiction of the sound through onomatopoeia, and the physical steps themselves are shown to us. When Eric 2 crawls through a tunnel made of print texts, the reader is shown the map and the path that he takes (227). Between the description of Eric 2's looking at the map and the reader's reception of the map exists a temporal moment as narration becomes image, but also a spatial gap between the text and the image. This also occurs when Eric 2 falls into an ocean: textual narration is suspended and slips into a visual representation of the Ludovician coming forward to attack (328-373). The very real time and space between which modes occur and modes are comprehended therefore operate in literature as liminal phenomena between both narrative time and narratological space. These examples establish a relationship between language and image, demonstrating what Carey Jewitt and Gunther Kress call the dominance of visual images in contemporary methods of meaning-making $(2003,16)$.

The Raw Shark Texts invokes a paradigm of media convergence in its imitation of digital code and digital ontologies. Conceptual fish such as the Ludovician live in a world that is compared to water. It is described as an "immense latticework of lakes and flowing streams, [...] [a] waterway paradise of all information and identities and societies and selves" (Hall 2007, 55); like the internet, it is an information highway. This space is directly contrasted with the material world, especially with analogue objects. For example, when the Ludovician attacks Eric 2 for the first time, the narration distinguishes between the concrete 'hard' quality of the material 
world and the ephemeral, liquid space of information that Eric 2's living room suddenly transforms into (59). When Eric 2 escapes, a tower of books crashes onto his head. That is, print, as an analogue form, smashes into him when he escapes the information water.

This example serves as a comment on the current tensions between print culture and digital media culture, which are here set up as oil and water that can cancel out one another. The novel highlights the concern that we may become overwhelmed by digital media, as when the Ludovician appears on Eric 2's television screen and manages to turn his entire material living room into water (58). As we have invented digital media by injecting them with once-concrete and analogue information, in The Raw Shark Texts these media begin to give birth to digital organisms. The image of a mosquito in The Raw Shark Texts, for instance, is made of computer code, functioning as a reminder that digital artefacts are composed of computer language (96). Imagining that internet users are not conscious enough of the role of code in creating digital artefacts, Kenneth Goldsmith emphasizes that all things digital, when stripped stark naked and revealed for what they are, take on the overwhelming discourse of code; for example, he shows that the Wikipedia favicon, or bookmark icon, is composed of multiple lines of code $(2011,21)$. Digital artefacts come alive in The Raw Shark Texts, but the novel is careful to demonstrate that they are not organic; even their nuclei are composed of information. Eric 1 reflects in a letter to Eric 2 that these organisms are our creation: "The streams, currents, and rivers of human knowledge, experience, and communication which have grown throughout our short history are now a vast, rich, and beautiful environment. Why should we expect these flows to be sterile?" (Hall 2007, 64). Two things are implied in this description: first, anthropomorphism or the furnishing of non-human objects with human attributes, and second, the identification of posthumanism as a consequence of technological determinism.

The idea that our digital information is not sterile and is in fact capable of reproduction, and also that these organisms can attack us, ascribes a consciousness to the organisms. Hayles highlights that posthumanism is in fact not a dystopic theory but a theoretical reality. She argues that the agency of digital technology resides in binary code $(2008,183)$. Although humans created computer code, no single person can understand it all; so it attains its own 'language' of ones and zeros and slips into what Hayles calls a "sophisticated cognition" (185), its own consciousness. This means that the new media language described by Manovich is not only active, but that it also overwhelms human cognition and management. The meanings that we assign to concepts and signified objects manifest themselves in the conceptual world of the Ludovician. Is this not what already occurs when we input information into the computer? Does the information not produce digital artefacts? The capacity for production is what gives birth to the conceptual fish, which are likened to computers. Eric 1 tells Eric 2: "millions of words and ideas and concepts are constantly evolving. It doesn't seem too implausible that one of them elevated itself above its single cellular cousins in much the same way we did. 
The Selfish Meme?" (Hall 2007, 64). Eric 1's Darwinian understanding of information suggests that our privileging of technology has mutated within our digital media and digital artefacts. These media and artefacts have become stronger, faster, and are generally better at managing and processing information (Goldsmith 2011, 15).

The novel suggests that we may not recognize the potential of our digital media to mutate in this way. While Eric 2 insists that the Ludovician is clever and is strategically playing dead, Dr. Trey Fidorous, a master and medical doctor of language, insists that it is a "big stupid eating machine" (Hall 2007, 384). In fact, the shark, as is the case with many digital media, is not a stupid machine. These media do not always do what they are asked, a fact to which anyone who has ever experienced the 'blue screen of death' can testify. The autonomy of digital artefacts and media is demonstrated in Eric 1's own failed attempt to use the Ludovician to preserve and resurrect Clio. Instead, the 'clever' shark chooses to attack Eric 1.

His memory is lost, his identity is split into past and present. In effect, Eric 2 cannot locate the limits of his identity that would define who he was or who he is. He cannot find spatial limits, as he fails to control the conceptual space in which he had hoped to preserve Clio. He cannot locate defined and contained limits of language either: the QWERTY code, Morse code, and the organisms made of data overwhelm him because he has lost control over language. That is, his agency concerning human language has been affected by the language of new media. Already in 1979, Jean-François Lyotard identified the capacity of information technologies to alter thought and meaning-making and to aid self-legitimating information systems that render humans dialectically impotent. Systematic technology, Lyotard notes in The Postmodern Condition, impacts our language through the introduction of technologically informed logic such as that of postindustrial efficiency $(1984,46)$. In the digital age, this efficiency has created what we call a 'just-in-time' logic, an instantaneous gratification of information that is only supported by the automated and generative powers of new media (Manovich 2001, 36). Alan Liu has examined in depth how new technologies in a postindustrial, globalized, digitalized, and 'cool' world do not honour human memory or human history (2004, 2, 6), and it is the memory and history of Eric 1 that the shark hunts and consumes.

Eric 2 is therefore dialectically impotent and is stripped of his ability to speak about his emotions. When he meets a woman named Scout, who saves him from the Ludovician's second attack, he finds that he is attracted to her and has an intuitive feeling that he already knows her. When he discovers that she has a tattoo of a smiley face on her big toe, a tattoo that Clio had meant to have done, Eric 2 realizes that Scout fits Eric 1's descriptions of Clio. Struggling between observations of Scout and representations of Clio, he loses control of language, and both he and Scout often speak in a way that is clipped, garbled, or nonsensical. When his feelings start to bubble up, he often mutters "Erm" to her. In fact, when they are 
about to kiss for the first time, Scout looks up at him and whispers romantically, "Erm..." (Hall 2007, 210). "Erm" then becomes a signifier for the lack of language between the two.

In addition, rather than expressing the growing feelings that he has for Scout, Eric 2 says over and over that he feels "something" - something that is beyond his limits and his reach. When he first realizes that he is attracted to Scout, he narrates, "something flared inside me, something distant, different, familiar, alien. A ghost of something" (164). Eric 2 states that he can feel in the back part of his brain and in his heart an uncanny recognition - uncanny in that it is a hauntingly familiar and yet desperately distant feeling, the uncanny presence of Scout as a spectral form of Clio. After they have slept together for the first time, this "something" suggests to him that he and Scout have done this before and that she may in fact be Clio. Engaging in an inner dialogue with himself and that uncanny something, he ponders: "What if I told her about the other thing, the hidden thing, the nonsense thing? The thing that insisted that she was connected to Clio Aames. Connected? Go on, say $i t$. The thing that insisted - go on say it - she was Clio Aames" (303; emphasis in the original).

When the Ludovician is killed, language comes back to Eric 2. Whether or not this return is a direct cause of the Ludovician's death remains ambiguous, but this is strongly suggested through the digital symbolism and information overload associated with the shark. These uncanny reflections are named when Eric 2 believes that Scout is also dead and mutters out to the sea, "Scout," and then, "Clio" (415). When she appears out of the water, words come rushing to him: "Everything came together then. The whispering nonsense and that huge something I hadn't been able to find, all of it focusing into one bright, brilliant realisation" (424; emphasis in the original). Eric 2 says in succession, "Oh God," "Thank you," and finally "I love you" (424). He identifies and vocalizes the "something," giving language to what he feels. This "something," the lost language, returns to him as a language of humanity.

The critical and cultural value of novels such as The Raw Shark Texts is that they speak to the implications of digital textuality on how we communicate, especially with regard to increasing anxieties in literary and print cultures about generative creative texts. The very notion that a creative text can be produced by a machine sucks the humanity out of the text and reiterates the argument that new media have attained a consciousness through language. However, Selmer Bringsiørd and David A. Ferrucci have stressed vehemently that the machine can never write a text like a human can, simply because it lacks humanity - the ability to reflect and feel in the process of writing (qtd. in Fitzpatrick 2002, 544).

This is something to be stressed: the role of the human in the culture or text of convergence, the role of the human in reflecting and critiquing such culture and such text. As a part of digital and convergence culture, we recognize posthumanism in automated machines that break down borders so that the reader is a user, and the user utilizes the language of digital media. Yet cultural texts such as litera- 
ture act as reflections and representations of culture, helping us to keep an acute sense of who it is that speaks, writes, and tells stories; who it is that still understands; and whose stakes are on the line if such borders are to be shifted.

\section{Works Cited}

Aufderheide, Patricia. "Creativity, Copyright, and Authorship." Media Authorship. Ed. Cynthia Chris and David A. Gerstner. New York: Routledge, 2013. 21-36.

Chaouli, Michel. "How Interactive Can Fiction Be?" Critical Inquiry 31.3 (2005): 599-617.

Chun, Wendy Hui Kyong. "Introduction: Did Somebody Say New Media?" New Media, Old Media: A History and Theory Reader. Ed. Wendy Hui Kyong Chun and Thomas Keenan. Oxon and New York: Routledge, 2006. 1-10.

Cranny-Francis, Anne. MultiMedia: Texts and Contexts. London: SAGE, 2005.

Fitzpatrick, Kathleen. "The Exhaustion of Literature: Novels, Computers, and the Threat of Obsolescence.” Contemporary Literature 43.3 (2002): 518-559.

Gibbons, Alison. "The Narrative Worlds and Multimodal Figures of House of Leaves: "-find your own words; I have no more." Intermediality and Storytelling. Ed. Marina Grishakova and Marie-Laure Ryan. Göttingen: Hubert, 2010. 285311.

---. "Multimodality." Multimodality, Cognition, and Experimental Literature. New York: Routledge, 2012. 8-25.

Gitelman, Lisa. "Introduction: Media as Historical Subjects." Always Already New: Media, History, and the Data of Culture. Cambridge: MIT Press, 2008. 1-22.

Goldsmith, Kenneth. "Revenge of the Text." Uncreative Writing. New York: Columbia UP, 2011. 14-33.

Grishakova, Marina. "Intermedial Metarepresentations." Intermediality and Storytelling. Ed. Marina Grishakova and Marie-Laure Ryan. Göttingen: Hubert, 2010. 312-332.

Hall, Steven. The Raw Shark Texts. New York: Canongate, 2007.

Hayles, N. Katherine. "The Future of Literature: Print Novels and the Mark of the Digital." Electronic Literature: New Horizons for the Literary. Notre Dame: U of Notre Dame, 2008. 159-186.

Herman, David. "Towards a Transmedial Narratology." Narrative across Media: The Language of Storytelling. Ed. Marie-Laure Ryan. Lincoln: U of Nebraska P, 2004. 47-75. 
Jenkins, Henry. Convergence Culture: Where Old and New Media Collide. 2006. New York: New York UP, 2008.

Jewitt, Carey, and Gunther Kress. Introduction. Multimodal Literacy. New York: Peter Lang, 2003. 1-18.

Kirschenbaum, Matthew G. Mechanisms: New Media and the Forensic Imagination. Cambridge: MIT Press, 2008.

Kress, Gunther. "Multimodality, Multimedia and Genre." Literacy in the New Media Age. London: Routledge, 2003. 105-119.

---. "Mode." Multimodality: A Social Semiotic Approach to Contemporary Communication. London and New York: Routledge, 2010. 79-102.

Landow, George P. "Hypertext and Critical Theory." Hypertext 3.0. Baltimore: John Hopkins UP, 2006. 53-67.

Lankshear, Colin, and Michele Knobel. "Introduction: Digital Literacies Concepts, Policies and Practices." Digital Literacies: Concepts, Policies and Practices. New York: Peter Lang, 2008. 1-16.

Lim, Sun Sun, Elmie Nekmat, and Siti Nurharnarni Nahar. "The Implications of Multimodality for Media Literacy." Multimodal Studies: Exploring Issues and Domains. Ed. Kay O'Halloran and Bradley A. Smith. New York: Routledge, 2011. 169-183.

Liu, Alan. "Literature and Creative Destruction." The Laws of Cool: Knowledge Work and the Culture of Information. Chicago: U of Chicago P, 2004. 1-10.

Lunenfeld, Peter. "Unfinished Business." The Digital Dialectic: New Essays on New Media. 1999. Ed. Peter Lunenfeld. Cambridge, MA and London, UK: MIT Press, 2001. 6-22.

Lyotard, Jean-François. The Postmodern Condition. 1979. Trans. Geoff Bennington and Brian Massumi. Manchester: Manchester UP, 1984.

Manovich, Lev. The Language of New Media. Cambridge, MA: MIT Press, 2001.

Morris, Adalaide. "New Media Poetics: As We May Think/How to Write." New Media Poetics: Contexts, Technotexts, and Theories. Ed. Adalaide Morris. Cambridge: MIT Press, 2009. 1-45.

Nerone, John. "The Future of Communication History." Critical Studies in Media Communication 23.3 (2006): 254-262.

Nørgaard, Nina. "Multimodality and the Literary Text: Making Sense of Safran Foer's Extremely Loud and Incredibly Close." New Perspectives on Narrative and Multimodality. Ed. Ruth Page. London and New York: Routledge, 2009. 115126. 
Perloff, Marjorie. "Screening the Page/Paging the Screen: Digital Poetics and the Differential Text." New Media Poetics: Contexts, Technotexts, and Theories. Ed. Adalaide Morris. Cambridge: MIT Press, 2009. 143-164.

Robertson, Frances. "Conclusion: Post-Print Culture?" Print Culture: From Steam Press to Ebook. Oxon and New York: Routledge, 2013. 118-132.

Ryan, Marie-Laure. "Beyond Myth and Metaphor: Narrative in Digital Media." Poetics Today 23.4 (2002): 581-609.

---. "Will New Media Produce New Narratives?" Narrative across Media: The Language of Storytelling. Ed. Marie-Laure Ryan. Lincoln: U of Nebraska P, 2004. 337-359.

---. "Fiction, Cognition, and Non-Verbal Media." Intermediality and Storytelling. Ed. Marina Grishakova and Marie-Laure Ryan. Göttingen: Hubert, 2010. 8-26.

Unsworth, Len, and Chris Clérigh. "Multimodality and Reading: The Construction of Meaning through Image-Text Interaction." The Routledge Handbook of Multimodal Analysis. London and New York: Routledge, 2009. 151-164. 